ISSN: 0213-2060

DOI: https://doi.org/10.14201/shhme2018361135160

\title{
LA PROVISIÓN DE CANONICATOS Y DEL OBISPADO EN MALLORCA DURANTE EL REINADO DE FERNANDO II EL CATÓLICO (1479-1516)
}

\author{
The Nomination of Canons and Bishops in Majorca during the Kingdom \\ of Ferdinand II the Catholic (1479-1516)
}

\author{
Albert CASSANYES ROIG \\ Dept. d'Història. Facultat de Lletres. Universitat de Lleida. Plaça de Victor Siurana, 1. E-25003 LLEIDA. \\ C.e.:albert.cassanyes@historia.udl.cat
}

Recibido: 2016-12-18

Revisado: 2017-10-05

Aceptado: 2018-05-18

RESUMEN: El cabildo catedralicio era una de las instituciones eclesiásticas más importantes de Mallorca durante la Baja Edad Media. Estaba integrado por un total de veintidós canónigos, elegidos por los mismos prebendados. Sin embargo, tanto papas como reyes habían ido interviniendo cada vez más en su elección. Por otro lado, la designación del obispo era de mayor interés por su rol político y económico. Fernando II tuvo especial cuidado en nombrar para la cátedra mallorquina a clérigos cercanos a él. El presente artículo tiene por objetivo determinar la nómina de titulares que conformaron el cabildo de Mallorca durante el reinado de Fernando II y estudiar la influencia del monarca en la elección tanto de los canónigos como de los prelados en esta diócesis insular.

Palabras clave: Beneficios eclesiásticos; Cabildo catedralicio; Derecho de súplica; Fernando II el Católico; Mallorca.

ABSTRACT: The cathedral chapter was one of the most important ecclesiastical institutions in Majorca at the end of the Middle Ages. It was formed by a total of twentytwo canons who were elected by the canons themselves. Nevertheless, popes and kings had 
LA PROVISIÓN DE CANONICATOS Y DEL OBISPADO EN MALLORCA DURANTE

increasingly been intervening in their election. Notwithstanding, the appointment of bishops was more interesting due to their important political and economic role. King Ferdinand II took special care to designate clergymen close to him to the Majorcan Episcopal dignity. This paper has the aim of determining an onomastic list of the canons that formed the cathedral chapter during the reign of Ferdinand II and considering the influence of the king in the elections of the canons and the bishops in this insular diocese.

Keywords: Ecclesiastical prebends; Cathedral chapter; Right of request; Ferdinand II the Catholic; Majorca.

SUMARIO: 0 Introducción. 1 Los canónigos de Mallorca durante el reinado de Fernando II. 2 El acceso al canonicato: una cuestión entre el rey, el papa y el cabildo. 3 Los obispos de Fernando el Católico. 4 Conclusiones. 5 Referencias bibliográficas.

\section{$0 \quad$ INTRODUCCIÓN}

El rey Juan II de Aragón falleció en Barcelona el 19 de enero de 1479 y fue sucedido por su hijo Fernando, ya rey de Sicilia desde 1468. Además, desde hacía cinco años, el nuevo monarca también era rey consorte de Castilla en virtud de su matrimonio con Isabel I en $1469^{1}$. Los dos soberanos llevaron a cabo una importante actividad política destinada al fortalecimiento del poder real en detrimento de los otros estamentos, especialmente la nobleza ${ }^{2}$. Sin embargo, también pretendieron controlar la Iglesia y ejercer su influencia sobre ella ${ }^{3}$. A tal efecto, se promovió una reforma religiosa que buscaba el sometimiento de los eclesiásticos a los intereses regios al mismo tiempo que se promocionaba la virtud entre el clero secular y regular ${ }^{4}$. Esta política reformista en el ámbito religioso y el elevado grado de intervencionismo de la monarquía en la Iglesia, junto a la

1 Una síntesis de las negociaciones relativas al matrimonio entre Isabel de Castilla y Fernando de Aragón en Val Valdivieso, María Isabel del. «Isabel la Católica. Una mujer para el trono de Castilla». Memòries de la Reial Acadèmia Mallorquina d'Estudis Genealògics, Heràldics i Històrics, 2004, vol. 14, pp. 12-21.

2 La bibliografía sobre los Reyes Católicos es muy abundante y sería imposible el ejercicio de agrupar, en una nota a pie de página, las obras más importantes al respecto. Una buena síntesis del período es Ladero Quesada, Miguel Ángel. La España de los Reyes Católicos. Madrid: Alianza, 2005.

3 Lop OTín, María José. El cabildo catedralicio de Toledo en el siglo XV: aspectos institucionales y sociológicos. Madrid: Universidad Complutense de Madrid, 2001 (tesis doctoral), pp. 353-354. Sobre la relación entre la Iglesia y los estados premodernos -sobre todo, Castilla-, Nieto Soria, José Manuel. Iglesia y génesis del estado moderno en Castilla (1369-1480). Madrid: Editorial Complutense, 1993.

${ }_{4}$ Nieto Soria, Iglesia y génesis, pp. 381-412. Sobre la política reformista de los Reyes Católicos, véanse las publicaciones generales de GARCía Oró, José. La reforma de los religiosos españoles en tiempo de los Reyes Católicos. Valladolid: Instituto Isabel la Católica de Historia Eclesiástica, 1969; García Oró, José. Cisneros y la reforma del clero español en tiempo de los Reyes Católicos. Madrid: Consejo Superior de Investigaciones Científicas, 1971; Fernández de Córdoba Miralles, Álvaro. Alejandro VI y los Reyes Católicos. Relaciones politico-eclesiásticas (1492-1503). Roma: Edizioni Università della Santa Croce, 2005, pp. 605-654. 
LA PROVISIÓN DE CANONICATOS Y DEL OBISPADO EN MALLORCA DURANTE EL REINADO DE FERNANDO II EL CATÓLICO (1479-1516)

ALBERT CASSANYES ROIG

ya mencionada renovación política, permite considerar el reinado de los Reyes Católicos como el período de transición hispánica desde un territorio basado en una estructura medieval al nuevo estado moderno 5 .

Uno de los territorios que Fernando II heredó de su padre fue el Reino de Mallorca. El archipiélago balear constituyó siempre un dominio marginal de la monarquía, aunque muy importante por lo que se refiere a la política mediterránea del rey católico ${ }^{6}$. A nivel eclesiástico, las islas de Mallorca y Menorca conformaban una diócesis propia desde la conquista cristiana de 1229. Además, presentaban la peculiaridad de que dependían directamente de la Santa Sede 7 . Esta situación se truncó en 1492, cuando el obispado de Mallorca fue anexado a la nueva archidiócesis de Valencia, consecuencia de la promoción de la diócesis valentina a la categoría de arzobispado llevada a cabo por el papa Inocencio VIII, luego confirmada por el valenciano Alejandro $\mathrm{VI}^{8}$.

El presente artículo contiene dos partes bien diferenciadas. La primera quiere ser una sistematización de los canónigos que integraron el cabildo catedralicio de Mallorca durante el reinado de Fernando II. Así pues, se pretende fijar la nómina de los titulares de las canonjías, así como ofrecer algunos esbozos sobre el funcionamiento de la institución canonical. Por otro lado, la segunda parte se centra en la provisión de las prebendas

5 La categoría historiográfica de "estado moderno» ha dado lugar a una amplia bibliografía a nivel internacional. No es este el lugar apropiado para desarrollar un extenso estado de la cuestión, aunque hay que mencionar algunas referencias destacables. En primer lugar, la clásica obra de STRAYER, Joseph R. Sobre los orígenes medievales del Estado moderno. Barcelona: Ariel, 1986. Un poco anteriores son las reflexiones sobre este concepto historiográfico de Clavero Salvador, Bartolomé. «Institución, política y derecho. Acerca del concepto historiográfico de "Estado Moderno"”. Revista de Estudios Políticos, 1981, vol. 19, pp. 43-57. Algunas aportaciones interesantes, y más recientes, son MARKs, Robert B. Los origenes del mundo moderno. Una nueva visión. Barcelona: Editorial Crítica, 2007; y CePEDA AdÁN, José. En torno al concepto del estado en los Reyes Católicos. Madrid: Fundación Española de Historia Moderna-Consejo Superior de Investigaciones Científicas, 2010 (especialmente el capítulo «De la Edad Media a la Moderna", pp. 37-54).

6 SÁnchez Doncel, Gregorio. Presencia de España en Orán (1509-1792). Toledo: Estudio Teológico de San Ildefonso, 1991, pp. 99-172; Bello León, Juan Manuel. «Apuntes para el estudio de la influencia del corso y la piratería en la política exterior de los Reyes Católicos». Historia. Instituciones. Documentos, 1996, vol. 23, pp. 77-84; Martín Corrales, Eloy. «La defensa de las costas, del tráfico marítimo y de los súbditos frente al corso musulmán en la España de la Edad Moderna». Coloquio de Historia Canario-Americana, 2008, vol. 17, pp. 1854-1882. Mallorca jugó un rol esencial en la conquista de Bugía de 1510. DeYÀ BauzÀ, Miquel J. «Entre la toma de Orán y los pactos con Argel: las Baleares y la conquista de Bugía». En Bunes Ibarra, Miguel Ángel de y Alonso Acero, Beatriz (coords.). Orán. Historia de la corte chica. Madrid: Polifemo, 2011, pp. 55-82.

7 En cambio, Ibiza era una parroquia de la archidiócesis de Tarragona, pues había sido conquistada en 1235 por el arzobispo electo Guillem de Montgrí, en asociación a Nuño Sancho, conde del Rosellón, y al infante Pedro de Portugal. Marí Cardona, Joan. La conquesta catalana de 1235. Ibiza: Institut d'Estudis Eivissencs, 1976.

8 Navarro Sorní, Miguel. «La creación de la archidiócesis valentina. La Iglesia valenciana en el siglo XV». Anales Valentinos, 1992, vol. 18, pp. 287-304. También dependía de Valencia la diócesis de Cartagena: Olivares Terol, María José. «El obispado de Cartagena-Murcia y su cabildo catedralicio. Formación y evolución en el transcurso de la Edad Media». Anuario de Estudios Medievales, 1997, vol. 27, p. 1153. 
LA PROVISIÓN DE CANONICATOS Y DEL OBISPADO EN MALLORCA DURANTE

superiores de la Iglesia mallorquina -el obispado y los canonicatos- y las intervenciones que el papa, el rey y los propios canónigos llevaron a cabo a la hora de cubrir las vacantes. Todo ello permitirá una primera visión de conjunto del cabildo catedralicio en el período del tránsito a la Modernidad, así como una aproximación a su respuesta a la injerencia religiosa que, a pesar de no constituir una novedad", la monarquía católica iba efectuando en este ámbito.

Cabe indicar que una parte de los canónigos que se mencionarán ya han sido introducidos en un primer estudio prosopográfico realizado en otra aportación, cuyas conclusiones son perfectamente aceptables para el presente artículo ${ }^{10}$. Por este motivo, no se ha querido elaborar un nuevo análisis prosopográfico completo que incluyera los prebendados a partir del cambio de centuria. En cambio, se ha optado por un estudio centrado en el acceso a las prebendas, pues esta es una cuestión suficientemente relevante y trascendente como para exigir un análisis propio. Por otro lado, algunos de los canónigos que aparecerán a lo largo de las páginas siguientes ya fueron estudiados a nivel individual -y también con un objetivo prosopográfico- en una reciente publicación de Maria Barceló y Gabriel Ensenyat, en el marco de sus investigaciones sobre la recepción del humanismo en Mallorca ${ }^{11}$.

La principal fuente utilizada para la elaboración del presente artículo ha sido la serie documental «Actas Capitulares» del Arxiu Capitular de Mallorca. Para la cronología del reinado de Fernando II se conservan cuatro registros. Sin embargo, su información es desigual, a pesar de que están bastante completos y aportan cuantiosos datos de interés. La estructura de las actas es siempre la misma: la indicación de la fecha, la relación de los canónigos asistentes y la resolución que se acordó. A veces puede resumirse la deliberación realizada; en otras ocasiones, simplemente, se recoge la palabra Nibil tras el listado de asistentes, lo que indica, por tanto, que no se llegó a ningún acuerdo digno de ser apuntado. El latín es el idioma en que se hallan redactados la gran mayoría de los documentos; excepcionalmente, se encuentran algunas transcripciones de cartas reales u otros escritos en catalán o castellano. A partir de las actas capitulares, pues, se han ido recopilando los datos referentes a los distintos canónigos, así como a la injerencia del poder real o pontificio. Por otro lado, en el mencionado archivo catedralicio también se conserva el Llibre de Possessoris ${ }^{12}$, una sucesión de los canónigos que se inicia, precisamente, en el reinado de Fernando el Católico. Sin embargo, no se trata de una fuente contemporánea, sino que su formación fue posterior.

9 Los monarcas de la Corona de Aragón -como los de otros reinos europeos- pretendieron intervenir en la provisión de prebendas. Para el caso aragonés, es suficiente recordar la política de Pedro el Ceremonioso durante el Cisma de Occidente: el rey aprovechó su neutralidad para proveer los beneficios eclesiásticos vacantes. CASSANYES Roig, Albert. «Nicolau Espanyol: una canongia accidentada (1380-1391)». En Carbonell, Natàlia; Castaño, Marta; Duarte-Feitoza, Paulo H.; Perera Roura, Anna y Viñolas, Mariona (eds.). Investigar les Humanitats: viure a fons la humanitat. Girona: Universitat de Girona, 2016, pp. 51-52. También existen abundantes cartas de Alfonso el Magnánimo a la Santa Sede recomendando la concesión de prebendas a ciertos allegados.

10 Cassanyes Roig, Albert. «El Capítol catedralici de Mallorca a la segona meitat del segle XV». Anuario de Estudios Medievales, en prensa.

11 Barceló Crespí, Maria y Ensenyat Pujol, Gabriel. Clergues il.lustrats. Un cercle humanista a l'entorn de la Seu de Mallorca (1450-1550). Palma: Publicacions Catedral de Mallorca, 2013.

12 Su signatura es ACM, 15576. 
LA PROVISIÓN DE CANONICATOS Y DEL OBISPADO EN MALLORCA DURANTE EL REINADO DE FERNANDO II EL CATÓLICO (1479-1516)

ALBERT CASSANYES ROIG

Por este motivo, no se refieren todos los canónigos que poseyeron la prebenda canonical entre 1479 y 1516. En algunas ocasiones, incluso, se han podido corregir ciertos errores. Así pues, la combinación de ambas fuentes permitirá establecer la nómina de los canónigos mallorquines en el tránsito a la Modernidad y destacar las principales actuaciones que, en el nombramiento de prebendados, impulsó el rey católico.

\section{Los canónigos de Mallorca durante el reinado de Fernando II}

El cabildo catedralicio de Mallorca estaba integrado por veintidós canónigos -diez presbiterales, seis diaconiles y seis subdiaconiles- y cuatro dignidades -arcediano, sacrista, deán y precentor-. Sin embargo, no todos los prebendados residían en la diócesis. Cuando Fernando II accedió al trono en 1479, los canónigos más o menos presentes en Mallorca eran el arcediano Pere Gual, el sacrista Gabriel Cerdà, el deán Bartomeu Sureda, Nicolau Muñoz, Miquel López, Antoni Juan, Gabriel Valls, Gabriel Burguet, Joan Soldevila, Antoni Begur, Mateu Àlber, Gaspar Catllar, Esteve Descós, Antoni Busquets, Francesc Sala, Gaspar Llistó y Gaspar Albertí. Por su parte, el obispo de Mallorca poseía dos canonicatos ${ }^{13}$. En la Tabla 1 se indican los diferentes canónigos mallorquines durante el reinado de Fernando II. Ha sido posible fijar la sucesión completa en diez canonicatos; en los otros casos, se ha recogido el nombre del titular, indicándose, si se conoce, tanto el tipo de prebenda como su antecesor en la misma.

TABLA 1. Canónigos de Mallorca durante el reinado de Fernando II (1479-1516)

\begin{tabular}{|l|l|}
\hline Presbiteral & $\begin{array}{l}\text { Gabriel Cerdà }(15 / 8 / 1450-1491) \\
\text { Pere Sard }(19 / 11 / 1491-1501) \\
\text { Antoni Francesc Bartomeu }(25 / 2 / 1501-1505) \\
\text { Llorenç Anglada }(12 / 12 / 1505-16 / 5 / 1506) \\
\text { Juan Fernández de Cantalapiedra }(16 / 5 / 1506-1507) \\
\text { Llorenç Abrines }(15 / 11 / 1507-1552)\end{array}$ \\
\hline Presbiteral & $\begin{array}{l}\text { Pere Bertran }(23 / 5 / 1459-1486) \\
\text { Lleonard Miquel Vidal }(25 / 9 / 1486-1500) \\
\text { Perot Pons (3/8/1500-1549) }\end{array}$ \\
\hline Presbiteral & $\begin{array}{l}\text { Gaspar Llistó }(20 / 10 / 1474-1502) \\
\text { Guillem Grua }(10 / 1 / 1502-1525)\end{array}$ \\
\hline Presbiteral & $\begin{array}{l}\text { Nicolau Muñoz (...-1485) } \\
\text { Jaume Jeroni Salom }(1485-1525)\end{array}$ \\
\hline Presbiteral & $\begin{array}{l}\text { Esperandéu Espanyol (26/5/1465-1505) } \\
\text { Francesc Net (8/3/1505-1536) }\end{array}$ \\
\hline Presbiteral & $\begin{array}{l}\text { Arnau de Santacília }(1478 ?-c 7 / 12 / 1509) \\
\text { Nicolau Muntanyans }(9 / 8 / 1510-1564)\end{array}$ \\
\hline Diaconil & $\begin{array}{l}\text { Francesc Mília (1479-1492) } \\
\text { Lluís Guallats (19/8/1492-1497) } \\
\text { Miquel Gual (4/3/1499-1538) }\end{array}$ \\
\hline
\end{tabular}

13 En 1515 el cabildo decidió iniciar el proceso para desunir uno de los dos canonicatos vinculados al obispo. ACM, 01-10-ACA-019, fols. 210v-211v y 213r. 
LA PROVISIÓN DE CANONICATOS Y DEL OBISPADO EN MALLORCA DURANTE

\begin{tabular}{|c|c|}
\hline Diaconil & Joan Soldevila (6/9/1468-1527) \\
\hline Subdiaconil & $\begin{array}{l}\text { Gabriel Burguet (12/4/1466-15/10/1507) } \\
\text { Jaume Arnau Burguet }(1 / 3 / 1508-1518)\end{array}$ \\
\hline Subdiaconil & $\begin{array}{l}\text { Antoni Busquets }(16 / 12 / 1477-1490) \\
\text { Antoni Joan Busquets }(1490-1522)\end{array}$ \\
\hline & 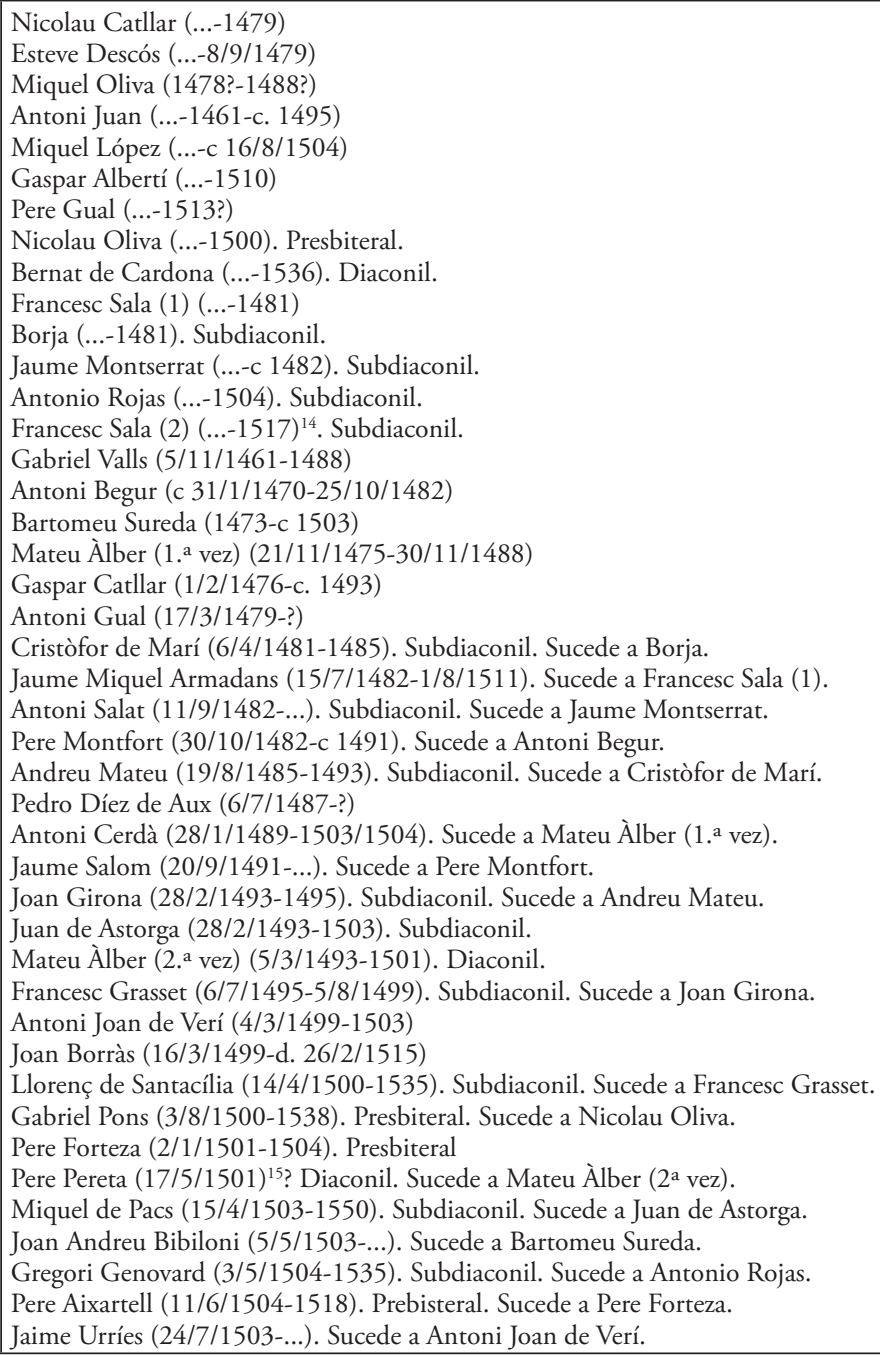 \\
\hline
\end{tabular}

14 No se trata del mismo Francesc Sala que era canónigo en 1479, pues este falleció en 1481.

15 No parece que Pere Pereta llegara a tomar posesión del canonicato, pues, cuando Jeroni de Mília presentó sus cartas apostólicas, se indicó que la prebenda vacaba por muerte de Mateu Àlber, sin referencia alguna a Pereta. ACM, 01-10-ACA-018, fol. 81v. 
LA PROVISIÓN DE CANONICATOS Y DEL OBISPADO EN MALLORCA DURANTE EL REINADO DE FERNANDO II EL CATÓLICO (1479-1516)

ALBERT CASSANYES ROIG

\begin{tabular}{|l|l|}
\hline & Antoni Abelló $(\mathrm{c} 1505-\ldots)$ \\
Gaspar Pou $(11 / 4 / 1505-\ldots)$ \\
Jeroni de Mília $(26 / 4 / 1505-1549)$. Diaconil. Sucede a Pere Pereta. \\
Jaume Rovira $(5 / 7 / 1508-\ldots)$ \\
Arnau Albertí $(19 / 10 / 1510-\ldots)$. Sucede a Gaspar Albertí. \\
Miguel Alfaro $(7 / 10 / 1511-\ldots)$. Sucede a Jaume Miquel Armadans. \\
\hline
\end{tabular}

Como se puede observar en la nómina de canónigos presentada, buena parte de los prebendados pertenecía a importantes familias mallorquinas, tanto del estamento de la nobleza como del de los ciudadanos. Muchas de estas también controlaban las instituciones regnícolas. Fue el caso, por ejemplo, de los Sureda, los Gual o los Muntanyans, algunos de cuyos miembros ocuparon el cargo de jurado de la ciudad y del Reino de Mallorca en aquellos mismos años ${ }^{16}$. Por otra parte, hay que destacar también la representación de sagas de juristas que habían conseguido ascender al estamento de los ciudadanos. Este fue el caso de los Mília o de los ya mencionados Muntanyans, que tuvieron un importante rol en la vida política mallorquina ${ }^{17}$. Este fenómeno de aristocratización del cabildo catedralicio no es particular para Mallorca, sino que también se puede documentar en otros reinos hispánicos ya desde el siglo $\mathrm{XIV}^{18}$. Tampoco hay que olvidar la frecuente aprobación de estatutos y normativas internas que exigían un determinado origen social para poder acceder a una prebenda catedralicia. Esta práctica limitaba la entrada de ciertos colectivos a la institución canonical y mantenía también la división social dentro del cabildo ${ }^{19}$.

Además de un origen acomodado, muchos canónigos habían cursado estudios universitarios ${ }^{20}$. La mayor parte poseía el grado de doctor en Cánones, como el deán Bartomeu Sureda o los canónigos Nicolau Muñoz, Arnau de Santacília o Joan de Soldevila, para citar algunos. Minoritarios, en cambio, eran los que habían obtenido el

16 Campaner y Fuertes, Álvaro. Cronicon Mayoricense. Noticias y relaciones históricas de Mallorca desde 1229 a 1800. Palma de Mallorca: [Edic. de Ayer] 1967, pp. 201-202. Sobre los jurados, véase Planas Rosselló, Antonio. Los jurados de la Ciudad y Reino de Mallorca (1249-1718). Palma: Lleonard Muntaner, editor, 2005.

17 Sobre estas importantes familias de juristas, véanse Palou Santandreu, Jaume. «Els Montanyans i el cercle d'humanistes. Una família poderosa a finals de l'Edat Mitjana». En Barceló Crespí, Maria (coord.). Al tombant de l'Edat Mitjana. Tradició medieval i cultura humanista. Palma: Institut d'Estudis Baleàrics, 2000, pp. 451-468; Barceló Crespí, Maria y Ensenyat Pujol, Gabriel. «Els Mília. Una altra nissaga de notaris a la Mallorca medieval». En Ferrando Ballester, Catalina (ed.). Homenatge a Guillem Rosselló Bordoy. Palma: Govern de les Illes Balears, 2002, pp. 177-191.

18 Guijarro GonzÁlez, Susana. "Jerarquía y redes sociales en la Castilla medieval: la provisión de beneficios eclesiásticos en el cabildo de la catedral de Burgos (1390-1440)». Anuario de Estudios Medievales, 2008, vol. 38, n. ${ }^{\circ}$ 1, pp. 296-297; DíAz IвÁŃEz, Jorge. «Iglesia y nobleza en la Sevilla bajomedieval». Anuario de Estudios Medievales, 2009, vol. 39, n. ${ }^{\circ}$ 2, pp. 881-882.

19 En Mallorca existía un estatuto por el cual solo podían ser canónigos las personas pertenecientes a la nobleza o las que contaran con un grado universitario. Xamena Fiol, Pere y Riera, Francesc. Història de l'Església a Mallorca. Palma: Editorial Moll, 1986, p. 82.

20 La Iglesia había favorecido que sus miembros -no solo los canónigos- cursaran estudios superiores. Así pues, permitía a los eclesiásticos percibir sus rentas a pesar de su ausencia. También otorgaba un lugar en el coro a los que hubieran obtenido el grado de doctor. 
LA PROVISIÓN DE CANONICATOS Y DEL OBISPADO EN MALLORCA DURANTE

doctorado en Leyes, como, por ejemplo, Pere Gual. Sí que hay documentados algunos casos de graduados en ambos Derechos, como el canónigo Arnau Albertí ${ }^{21}$, aunque no son muy numerosos. Tampoco abundaron los graduados en Teología, como lo fue Gaspar $\mathrm{Pou}^{22}$. En cualquier caso, se puede suponer que todos los canónigos que poseían un título universitario habían superado previamente los estudios de Artes y Filosofía -obligatorios para acceder a las «facultades mayores»-, aunque son muy escasas las referencias a prebendados con esta titulación; fue el caso de Francesc Net, maestro en Artes en el momento de acceder al canonicato ${ }^{23}$. Sin embargo, y a pesar de los estatutos, no era requisito indispensable contar con un título universitario, pues se hallan muchos prebendados, como Miquel López, Antoni Juan, Antoni Busquets o Andreu Mateu, de los que no se menciona grado alguno. En otras ocasiones, los propios canónigos podían estar estudiando mientras regían su prebenda. Así pues, el 17 de julio de 1504 se leyó en el cabildo un certificado, remitido por el rector del Estudio General de Huesca, en el que se indicaba que el canónigo Jaime de Urríes cursaba el grado en Derecho Canónico en el mencionado centro ${ }^{24}$. Por su parte, el 13 de octubre de 1512 el canónigo Nicolau Muntanyans solicitó que se le pagaran las distribuciones cotidianas a pesar de frecuentar el Estudio General, de acuerdo con los estatutos del cabildo ${ }^{25}$. Los estudios generales de Huesca y Mallorca, pues, fueron dos de los que frecuentaron los canónigos. Las fuentes no suelen indicar el lugar donde los prebendados obtuvieron sus grados. Lo más probable es que se continuara la tendencia observada para la segunda mitad del siglo Xv y que el centro de estudios más habitual en la península Ibérica fuera el Estudio General de Lérida, mientras que, en el exterior, se optara por alguna de las universidades del norte de Italia ${ }^{26}$.

Los canónigos tenían la función de gestionar todos los asuntos referentes a la catedral de Mallorca y, en ocasiones, a la entera Iglesia mallorquina, pues también ejercían como consejo asesor del obispo o, en caso de ausencia o de sede vacante ${ }^{27}$, asumían parte de sus funciones gubernativas. Por este motivo, era muy importante que los canónigos asistieran ordinariamente a las sesiones capitulares, de modo que la ausencia injustificada a las mismas implicaba que no se percibieran las rentas correspondientes a aquel día. En caso de enfermedad, se tenía que certificar la indisposición mediante un testigo y un acta notarial. También constituía un motivo justificado de ausencia

21 ACM, 01-10-ACA-019, fol. 84r.

22 ACM, 01-10-ACA-018, fol. 80r.

23 ACM, 01-10-ACA-018, fols. 76v-77r.

24 ACM, 01-10-ACA-018, fol. 45r.

25 ACM, 01-10-ACA-019, fol. 102r. No solo los canónigos apelaron a estos estatutos; también el diácono Joan Calbó solicitó el pago mientras cursaba estudios fuera de la isla. ACM, 01-10-ACA019, fol. 101v.

26 Cassanyes Roig, «El Capítol catedralici de Mallorca». Véase también el ilustrativo artículo de Ramis Barceló, Rafael. "Peregrinatio academica: legistas y canonistas de la Corona de Aragón en las universidades italianas durante el Renacimiento». Miscellanea Historico-Iuridica, 2014, vol. 13, pp. 35-66.

${ }_{27}$ El estado de sede vacante se declaraba tras la muerte, renuncia o traslado del obispo y hasta la toma de posesión del nuevo prelado, por lo que podían transcurrir años en esta situación. 
LA PROVISIÓN DE CANONICATOS Y DEL OBISPADO EN MALLORCA DURANTE EL REINADO DE FERNANDO II EL CATÓLICO (1479-1516)

ALBERT CASSANYES ROIG

hallarse oficiando misa en el altar correspondiente durante la reunión, lo que se hacía constar en una nota en la lista de asistentes. Asimismo, el cabildo tenía que autorizar a los canónigos sus salidas de Mallorca. Por ejemplo, el 5 de julio de 1483 los prebendados accedieron a que Gaspar Albertí viajara a Roma ${ }^{28}$. En cualquier caso, la ausencia de la isla implicaba que solo se percibiera la mitad de la porción canonical y ninguna parte de las distribuciones cotidianas, que constituían los dos principales ingresos de los prebendados. Igualmente, los canónigos ausentes de la isla no eran convocados a las sesiones capitulares, de acuerdo con una antigua costumbre a la que se apelaba al inicio de cada sesión.

El funcionamiento de las reuniones capitulares era siempre el mismo: se presentaba un tema al cabildo -por parte del obispo, de un canónigo, de un beneficiado o de una persona externa a la catedral- y este lo trataba y tomaba una resolución por mayoría de $\operatorname{votos}^{29}$. De forma excepcional, y siempre como medida punitiva, un canónigo podía ser privado de voz y voto en las sesiones capitulares ${ }^{30}$. Por otro lado, en ocasiones el cabildo podía proceder a designar una comisión, formada por un mínimo de dos canónigos, a la que se delegaba la toma de una decisión. De acuerdo con la bula de 26 de febrero de 1509, remitida por el papa Julio II, la convocatoria de la sesión tenía que ser efectuada por el obispo, por su vicario general o por su lugarteniente ${ }^{31}$, aunque la periodicidad de las sesiones no era regular. Sin embargo, los prebendados se reunían de forma muy frecuente. Parece ser que la lengua habitual en las reuniones era la catalana, aunque las actas se escribían en latín, a excepción de las transcripciones de documentos -las cartas reales solían ser en castellano- o de discursos orales ${ }^{32}$.

Como se ha indicado anteriormente, el cabildo catedralicio de Mallorca contaba con cuatro dignidades, que habían sido establecidas en el momento fundacional de la institución canonical -a excepción del deanato, dignidad creada en $1299^{33}-$. A pesar de que solían recaer en un canónigo de la misma catedral, la posesión de una prebenda no era un requisito para el acceso a aquellas. El ejercicio de las dignidades era vitalicio, de modo que solo vacaban tras la muerte o la renuncia del titular ${ }^{34}$.

28 ACM, 01-10-ACA-016, fol. 109v. No solo los canónigos debían pedir permiso para ausentarse de la isla: en 1510 el cabildo autorizó al hebdomadario Gabriel Vaquer a desplazarse a Roma. Al mismo tiempo, permitió que su sobrino Gabriel Vicens lo sustituyera durante cuatro meses. ACM, 01-10-ACA-018, fol. 211v.

29 Solo los canónigos tenían derecho de voto. Las dignidades solo formaban parte del cabildo si poseían, al mismo tiempo, una prebenda canonical, como era habitual. Por su parte, el obispo, a pesar de contar con dos canonicatos, solo tenía un voto. ACM, 01-10-ACA-018, fol. 180v.

30 En octubre de 1503 se inició un proceso contra Antoni Joan Busquets por haber injuriado de palabra a dos concanónigos. Además de nombrar a los adjuntos pertinentes, el cabildo también decidió privar al imputado de voz en las sesiones capitulares y de todas sus rentas catedralicias durante un año. ACM, 01-10-ACA-018, fol. 32r-v.

31 ACM, 01-10-ACA-018, fols. 180r-181v.

32 Por ejemplo, en ACM, 01-10-ACA-018, fol. 14r.

33 Cassanyes Roig, Albert. «El Capítol catedralici de Ramon Llull (1232-1316)». En Fullana Puigserver, Pere y Gambús Saiz, Mercè (coords.). Ramon Llull i la Seu de Mallorca. Palma: Publicacions Catedral de Mallorca, 2016, pp. 45-50.

34 Cassanyes Roig, «El Capítol catedralici de Mallorca». 
LA PROVISIÓN DE CANONICATOS Y DEL OBISPADO EN MALLORCA DURANTE EL REINADO DE FERNANDO II EL CATÓLICO (1479-1516) ALBERT CASSANYES ROIG

Tabla 2. Dignidades catedralicias durante el reinado de Fernando II (1479-1516)

\begin{tabular}{|l|l|}
\hline Arcediano & $\begin{array}{l}\text { Pere Gual (1461-1513?) } \\
\text { Cardenal Cornaro (1513-1520) }\end{array}$ \\
\hline Sacrista & Gabriel Cerdà (1453-1491) \\
& Jofré de Borja (1494) \\
& Francesc Grasset (1494-1499) \\
& Arnau de Santacília (1499-1510) \\
& Cardenal Pisco (1510) \\
& Nicolau Montanyans (1510-1565) \\
\hline Deán & Bartomeu Sureda (1472-1507) \\
& Jeroni Castellà (1507-1535) \\
\hline Precentor & $\begin{array}{l}\text { Joan de Borja (1478-1486) } \\
\text { César Borja (1486-1505) } \\
\end{array}$ \\
& Llorenç de Santacília (1505-1535) \\
\hline
\end{tabular}

Como se puede apreciar, los años de tránsito entre el cuatrocientos y el quinientos se caracterizaron por una elevada movilidad de los titulares de las dignidades, especialmente en el cargo de sacrista. Como se comentará más abajo, parte de estos cambios se pueden explicar por el interés en proveer las dignidades a personas fieles, cuando no a familiares. Será este el caso paradigmático de la familia Borja, algunos miembros de la cual se sucedieron en las dignidades de sacrista y de precentor. También hay que destacar la elevada presencia de personas de las cuales no hay constancia que también poseyeran una canonjía en la catedral de Mallorca. El hecho de que algunas de ellas fueran cardenales o parientes del papa -los ya mencionados Borja- es un indicativo de la importancia que la Santa Sede tuvo a la hora de proveer las vacantes, un hecho que se analizará a continuación.

\section{El ACCESO AL CANONICATO: UNA CUESTIÓN ENTRE EL REY, EL PAPA Y EL CABILDO}

El procedimiento de acceso a las canonjías se iniciaba al ocasionarse una vacante ${ }^{35}$. La forma más habitual era tras la muerte de su titular, atendiendo que los canonicatos eran vitalicios. Sin embargo, a veces pueden hallarse renuncias o resignaciones. Así lo hizo Francesc Sala, cuya renuncia en 1482 permitió a Jaume Miquel Armadans acceder a la canonjía ${ }^{36}$, o Juan de Astorga, que fue sucedido por Miquel de Pacs ${ }^{37}$. Asimismo, cuando un canónigo era promocionado al episcopado o a otra prebenda incompatible, debía renunciar a su canonicato, excepto en el caso que contara con una bula de compatibilidad otorgada por el papa ${ }^{38}$.

35 Iglesias Ortega, Arturo. «Cómo llegar a ser canónigo en el siglo xvi: formas de ingreso en el cabildo de la catedral de Santiago de Compostela». Cuadernos de Historia Moderna, 2014, vol. 39, pp. 78-81.

36 El canonicato le fue disputado por Arnau de Puigdorfila en un pleito que no terminó hasta el 28 de mayo de 1483 con la renuncia al proceso por parte de este. ACM, 01-10-ACA-016, fols. 85v, 97r-v y 109 r.

37 ACM, 01-10-ACA-018, fols. 22v-23r.

38 La acumulación de prebendas fue una práctica criticada por el Concilio III de Letrán (1179), aunque las numerosas dispensas papales concedidas para permitir la compatibilidad de beneficios 
LA PROVISIÓN DE CANONICATOS Y DEL OBISPADO EN MALLORCA DURANTE EL REINADO DE FERNANDO II EL CATÓLICO (1479-1516) ALBERT CASSANYES ROIG

Las resignaciones no solían ser desinteresadas, sino que, frecuentemente, buscaban facilitar el acceso a la prebenda de un pariente, respondiendo, por tanto, a una planificada estrategia familiar. A modo de ejemplo, Antoni Busquets resignó su canonicato en 1490 a favor de su sobrino Antoni Joan Busquets; más aún, el cabildo le entregó la misma casa en la que había residido su pariente ${ }^{39}$. También el canónigo Gabriel Burguet resignó su prebenda el 15 de octubre de 1507 a favor de su sobrino Jaume Arnau Burguet, aunque reservándose ciertos honores capitulares, como los referentes a su sepultura. A tal efecto, fue necesario solicitar y obtener una gracia especial del cabildo y una carta apostólica ${ }^{40}$. Un último ejemplo es el de Arnau Albertí, que sucedió a su pariente Gaspar Albertí en su canonicato el 19 de octubre de $1510^{41}$.

También se documentan algunas permutas -esto es, el procedimiento por el cual dos prebendados se intercambiaban sus respectivas sinecuras ${ }^{42}-$, aunque son muy escasas: en 1488 Mateu Àlber permutó su canonicato con Antoni Cerdà, aunque el 5 de marzo de 1493 volvió a acceder a una canonjía en Mallorca ${ }^{43}$. Esta permuta respondía a una estrategia familiar, pues Antoni Cerdà era pariente tanto de Mateu Àlber como del sacrista Gabriel Cerdà. No en vano, el mismo día en que Antoni Cerdà fue admitido al canonicato (28 de febrero de 1489), Gabriel Cerdà prometía abonar cierta cantidad a la fábrica de la catedral en el plazo de dos años ${ }^{44}$. A pesar de que no se indica el concepto del pago comprometido por el sacrista, es probable que Gabriel Cerdà se obligara a sufragar el monto que el nuevo canónigo tenía que abonar forzosamente en acceder al canonicato.

El procedimiento ordinario de acceso a la prebenda consistía en que, tras notificarse la vacante, las personas que podían tener derecho al canonicato presentaban sus solicitudes. Estas eran valoradas por el cabildo, que era el encargado de elegir, entre los que cumplieran los requisitos ${ }^{45}$, aquel que tuviera mayores razones. En todo caso, una vez admitido, el nuevo canónigo -o, más frecuentemente, su procurador- tenía que prestar juramento de observancia de los estatutos y costumbres de la catedral mallorquina y de obediencia al prelado ${ }^{46}$, y, a cambio, recibía el ósculo

dejaron sin efecto las medidas que se intentaron tomar para evitarla. IgLESIAs OrTega, Arturo. El cabildo catedralicio de Santiago de Compostela en el siglo XVI: aspectos funcionales y sociológicos de una élite eclesiástica. Santiago de Compostela: Universidade de Santiago de Compostela, 2010 (tesis doctoral), p. 308.

39 ACM, 01-10-ACA-016, fol. 188v.

40 ACM, 01-10-ACA-018, fols. 131v y 137r-138v.

41 ACM, 01-10-ACA-018, fol. 223r-v.

42 Guijarro GonZÁlez, "Jerarquía y redes sociales», pp. 276-279.

43 ACM, 01-10-ACA-016, fol. 190r.

44 ACM, 01-10-ACA-016, fol. 176r.

45 Ya se ha comentado que los miembros del cabildo tenían que pertenecer a familias acomodadas o contar con estudios universitarios. Por su parte, los reyes procuraron que los canónigos fueran naturales de sus reinos, principalmente para lograr su apoyo político y evitar la salida de oro del reino. Nieto Soria, Iglesia y génesis, pp. 345-349 y 354-356; Lop Otín, El cabildo catedralicio de Toledo, pp. 355-356.

46 Cuando un canónigo que había sido provisto de su prebenda en ausencia llegaba a Mallorca, debía prestar personalmente el juramento ante el cabildo, como hizo Francesc Mília el 23 de julio de 1483. ACM, 01-10-ACA-016, fol. 112r. 
LA PROVISIÓN DE CANONICATOS Y DEL OBISPADO EN MALLORCA DURANTE EL REINADO DE FERNANDO II EL CATÓLICO (1479-1516) ALBERT CASSANYES ROIG

de la paz de sus compañeros y se le asignaba un lugar tanto en el coro como en el aula capitular ${ }^{47}$.

A lo largo de este proceso, el cabildo también trataba sobre cualquier asunto normativo que afectara a los nuevos electos. Así pues, por ejemplo, el 25 de septiembre de 1486 aceptó la candidatura de Lleonard Miquel Vidal -presentada por su procurador Bartomeu Caldentey, profesor de Teología, y Andreu Ballester, subejecutor- a pesar de que contenía el denominado defectum etatis, lo que no constituía un impedimento para la obtención de la prebenda ${ }^{48}$. Pero, por otro lado, también era posible que se presentaran protestas varias contra la elección de un determinado canónigo. Así, cuando Miquel Gual accedió al canonicato en 1499, se interpuso un recurso a la provisión. Sin embargo, la totalidad del cabildo apoyó el nombramiento de Gual, sobre todo porque el abogado capitular había determinado que el canonicato había sido provisto correctamente ${ }^{49}$. Además, Gual contaba con una bula papal que le concedía la canonjía ${ }^{50}$. De hecho, la presencia de una autorización apostólica facilitaba sobremanera la admisión de un pretendiente al canonicato. Así se demuestra también en la promoción de Lluís Guallats: a raíz de la presentación de un documento pontificio, el abogado capitular, Nicolau Berard, consideró que no había nada que objetar a su provisión, a pesar de que su elección no cumplía de forma rigurosa con la normativa ${ }^{51}$.

El acceso al canonicato suponía un importante desembolso económico. Cuando Jaume Miquel Armadans accedió a la prebenda en 1482 tuvo que pagar al canónigo Gabriel Valls por la capa canonical (30 libras), al domero Pere Calders (5 libras), al sochantre Bartomeu Alcover (5 libras), al portero Bernat Sala (2 libras), al abogado del cabildo ( 2 florines de oro) y al notario Pere Llitrà ${ }^{2}$ (10 florines de oro o un ducado del mismo metal), además de obligarse a abonar a la fábrica de la catedral 22 libras y 10 sueldos en el plazo de dos años ${ }^{53}$. Estos mismos pagos eran los que tenían que costear todos los canónigos en acceder a su prebenda ${ }^{54}$. En ocasiones, se llegaba a acuerdos para que, en lugar de abonar todas las cantidades de una sola vez, estas les fueran descontadas de las rentas que percibían de la Mensa Capitular. Así lo aprobó el cabildo para Francesc

47 Para la provisión y colación de canonicatos, véase GujJarro González, «Jerarquía y redes sociales", p. 280.

48 ACM, 01-10-ACA-016, fol. 146r.

49 Era muy habitual que los canónigos trasladaran al abogado capitular cualquier cuestión que fuera un poco controvertida jurídicamente y que se dejaran guiar por su conclusión.

50 ACM, 01-10-ACA-017, fols. 27v-28r.

51 ACM, 01-10-ACA-016, fol. 186v.

52 Los Llitrà fueron una prestigiosa familia de notarios. Véase BArCeló Crespí, Maria. Els Llitrà. Una nissaga de notaris a la Mallorca baixmedieval. Palma: Lleonard Muntaner, editor, 2001. fol. $85 \mathrm{v}$.

53 Su padre, Jaume Armadans, fue fiador de los pagos de su hijo. ACM, 01-10-ACA-016,

54 En 1484 el cabildo decidió que Antoni Juan también pagara la mitad de la cantidad -esto es, 11 libras y 5 sueldos- a la fábrica, pues no la había abonado anteriormente porque había accedido a la canonjía mediante permuta de su canonicato en Girona con Jaume Oliver. ACM, 01-10-ACA016, fol. 118r. En 1501 se ordenó que no se colacionara ningún canonicato sin que se hubiera pagado previamente la cantidad acostumbrada a la fábrica de la catedral. Mateu Mairata, Gabriel. Obispos de Mallorca. Palma: Ediciones Cort, 1985, pp. 195-196. 
LA PROVISIÓN DE CANONICATOS Y DEL OBISPADO EN MALLORCA DURANTE EL REINADO DE FERNANDO II EL CATÓLICO (1479-1516) ALBERT CASSANYES ROIG

Mília en 1483, librando, a su vez, a su fiador, el presbítero Antoni Salat, de la garantía de pago que había contraído 55 .

Sin embargo, las sucesiones en los canonicatos no eran tan sencillas, pues entraban en juego varios actores ${ }^{56}$. Uno de ellos era el propio monarca. Precisamente, Fernando II e Isabel -del mismo modo que sus predecesores Trastámara ${ }^{57}$ - ejercieron con insistencia el denominado "derecho de súplica», que les permitía presentar sus pretendientes a los distintos beneficios y prebendas vacantes, aunque el papa se reservaba la potestad de no tenerlos en cuenta $^{58}$. A través de este derecho, los reyes buscaron promover sus allegados a los distintos cargos eclesiásticos, entre los cuales se encontraban los canonicatos ${ }^{59}$. Esta práctica ya se había ido desarrollando desde el siglo XIII, siempre con el objetivo final de contar con clérigos fieles y leales en los lugares de responsabilidad, además de colocar miembros de la propia familia o premiar los servicios de otras personas ${ }^{60}$. Se documentan algunas injerencias del poder real en la provisión de canonjías mallorquinas. Por ejemplo, en 1487 Fernando II escribió a los canónigos de Mallorca para que no pusieran obstáculos a la concesión de un canonicato a Pedro Díez de Aux, que era capellán y cantor de la Capilla Real. Además, instó al cabildo catedralicio a reconocer el privilegio de fructibus in absencia que presentaba el nuevo canónigo ${ }^{61}$. En otras palabras, la canonjía de Mallorca de Pedro Díez de Aux no era más que un premio a sus servicios, de modo que su capellán pasaría a percibir una serie de rentas. La presentación del privilegio de fructibus in absencia en el mismo momento de su promoción y la insistencia del rey en que fuera admitido conducen a pensar que Fernando II no deseaba separarse de su cantor y que tomó las medidas oportunas para que esto no ocurriera. A pesar de ello, no siempre el monarca se involucraba tanto en la promoción de sus allegados. Así sucedió en 1511, al fallecer el canónigo Jaume Armadans: Miguel Alfaro y el doctor en Cánones Jaume Rovira presentaron sus derechos a la vacante. Alfaro era capellán real y, como tal, solicitó ayuda al monarca, aunque no se documenta que Fernando el Católico insistiera tanto como había hecho con Pedro Díez de Aux. En cualquier caso, Miguel Alfaro fue provisto del canonicato vacante el 7 de octubre de $1511^{62}$.

Un segundo actor, aunque muy importante, era el papa, a quien, teóricamente, correspondía la provisión de cualquier beneficio o prebenda, aunque fue compartiendo

55 ACM, 01-10-ACA-016, fol. 115r.

56 Guijarro GonZÁLEZ, "Jerarquía y redes sociales», pp. 272-273.

57 Nieto Soria, Iglesia y génesis, pp. 357-362, para el caso de Castilla.

58 Pérez, Joseph. Isabel y Fernando. Los Reyes Católicos. Madrid: Nerea, 2001, p. 125. A pesar de ser una práctica habitual, el derecho de súplica no fue reconocido hasta 1421. Nieto SoRIA, Iglesia y génesis, p. 351; Lop Oтín, El cabildo catedralicio de Toledo, pp. 400-401. Fernando e Isabel intentaron ir más allá y conseguir el derecho de presentación, que obligaba al papa a escoger únicamente entre los candidatos propuestos por los monarcas. Fernández de Córdoba Miralles, Alejandro VI, pp. 539-540.

59 Aunque no solo. Fernando II promovió al maestro Bartomeu Caldentey a un beneficio que había fundado el obispo Antoni de Galiana. Parece ser que hubo algunas resistencias de la Mensa Episcopal a aquella designación, aunque en 1493 Caldentey obtuvo la prebenda. ACM, 01-10-ACA-016, fol. 190r.

60 Nieto Soria, Iglesia y génesis, p. 344; Lop Otín, El cabildo catedralicio de Toledo, pp. 352-354.

61 ACM, 01-10-ACA-016, fol. 157r-v.

62 ACM, 01-10-ACA-019, fols. 41v-47r. 
LA PROVISIÓN DE CANONICATOS Y DEL OBISPADO EN MALLORCA DURANTE

esta facultad con otros elementos ${ }^{63}$. A pesar de ello, el vicario de Cristo podía hacer uso de las «reservas pontificias», por las que retenía el otorgamiento de las prebendas cuya provisión o vacante respondieran a unas determinadas circunstancias ${ }^{64}$. Por otra parte, continuaba vigente el sistema de expectativas, aunque su uso parece limitado y no siempre observado. Fue el caso de Pere Aixartell, que presentó su expectativa el 24 de enero de $1500^{65}$. Poco después quedó vacante un canonicato por la muerte de Mateu Àlber. A pesar de la existencia de clérigos expectantes, entre los cuales el mencionado Aixartell, y de un indulto apostólico a favor de la Inquisición, la canonjía fue concedida a Pere Pereta el 17 de mayo de $1501^{66}$. En cualquier caso, Aixartell continuó haciendo valer su expectativa, y en 1503, tras la muerte del canónigo Antoni Joan de Verí, solicitó la nueva vacante. También se presentaron Pere Gormàs, que contaba igualmente con una expectativa, y Jaime Urríes, prepósito de Huesca e integrante de la Capilla Real. El cabildo, ante la imposibilidad de definirse, optó por remitir la causa a la Santa Sede, de modo que fuera el propio papa -o los auditores de la Rota- quien decidiera el titular de la disputada prebenda $^{67}$. El 31 de agosto de 1503 esta fue provista a Jaime Urríes, que había contado con el apoyo de Fernando el Católico; de hecho, el monarca había enviado cartas desde Medina del Campo y Barcelona solicitando la concesión de la canonjía a su allegado ${ }^{68}$.

El papa también podía interferir en la provisión de canonicatos mediante la entrega de privilegios a algunas personas - por ejemplo, mediante bulas de coadjutoría ${ }^{69}$-, a las Iglesias o a los obispos, cuando no al propio monarca ${ }^{70}$. Así sucedió en la provisión del canonicato que fue de Antoni Begur, fallecido el 25 de octubre de 1482. Ante la vacante, el obispo Diego de Avellaneda decidió utilizar un privilegio de alternativa concedido por el papa Sixto IV en 1476. A través de este, el pontífice autorizaba al prelado a proveer a una persona idónea libremente elegida una prebenda cuya vacante se hubiera producido en un mes par (febrero, abril, junio, agosto, octubre o diciembre) ${ }^{71}$. El obispo eligió a

63 Lop Otín, El cabildo catedralicio de Toledo, p. 343. Buena parte de la sociedad europea era contraria al proceso de centralización desarrollado a partir del pontificado de Aviñón, de modo que aceptaba un cierto control de la Iglesia por parte del monarca. Nieto Soria, Iglesia y génesis, pp. 21-24.

64 Por ejemplo, el papa se reservaba la colación de los beneficios cuyo titular hubiera fallecido en la Curia Romana, que hubiera renunciado a favor del pontífice o que hubiera sido destituido. También aquellas prebendas cuyo último poseedor hubiera sido designado por el papa. Rapp, Francis. La Iglesia y la vida religiosa en Occidente a fines de la Edad Media. Barcelona: Labor, 1973, p. 15.

65 ACM, 01-10-ACA-017, fol. 46v.

66 ACM, 01-10-ACA-017, fol. 83r-v.

67 ACM, 01-10-ACA-018, fols. 27r-28r.

68 ACM, 01-10-ACA-018, fols. 30r-31v.

69 Teóricamente, las coadjutorías eran un mecanismo para asignar una persona a un prebendado para que ejerciera las funciones que este no podía realizar, ya fuera por motivo de edad o de salud. Sin embargo, pronto se convirtieron en una forma de asegurar la sucesión del coadjutor en la prebenda. Iglesias ORTEGA, "Cómo llegar a ser canónigo», pp. 95-99.

70 Nieto Soria destaca la concesión pontificia, en 1478, de una gracia a los Reyes Católicos para otorgar ciertas prebendas dentro de sus reinos. Nieto Soria, Iglesia y génesis, p. 363. La merced no tuvo efectos en la Corona de Aragón, todavía gobernada por Juan II.

71 La concesión de la alternativa era «un recurso que empleó el pontífice para satisfacer a los reyes -sin concederles poderes especiales-». Fernández de Córdoba Miralles, Alejandro VI, p. 562. 
LA PROVISIÓN DE CANONICATOS Y DEL OBISPADO EN MALLORCA DURANTE EL REINADO DE FERNANDO II EL CATÓLICO (1479-1516)

ALBERT CASSANYES ROIG

Pere Montfort, doctor en ambos Derechos, canónigo de Huesca y vicario general en la archidiócesis de Zaragoza. La elección fue luego ratificada por el cabildo ${ }^{72}$.

Como era de esperar, las provisiones canonicales fueron motivo de enfrentamiento entre los varios actores implicados en estas. Por ejemplo, el 22 de abril de 1479, poco después de acceder al trono, Fernando II promulgó un bando por el que se prohibía la publicación de bulas, indultos u otro tipo de documento pontificio referentes a la provisión de beneficios con una renta superior a las ocho libras ${ }^{73}$. Se trata, pues, de una muestra del pulso entre el papa y el rey por el nombramiento de prebendados ${ }^{74}$.

Sin embargo, una de las provisiones más complejas fue la que desembocó en una contienda por el canonicato vacante por muerte de Antoni Francesc Bartomeu. El 12 de diciembre de 1505 el obispo Antonio de Rojas decidió conceder esta prebenda a Juan Fernández Cantalapiedra, bachiller en Artes, lo que fue sometido a valoración del cabildo. El sacrista Arnau de Santacília dijo que, atendiendo a que la colación de la misma correspondía tanto al obispo como a los canónigos, quería proponer un candidato: su sobrino Llorenç Anglada. Entonces fue necesario proceder a una votación. Anglada tuvo ocho apoyos, y Cantalapiedra seis. Sin embargo, los partidarios del obispo argumentaron que el canonicato vacante era presbiteral, de modo que tenía que ser concedido a un presbítero, orden que Anglada no había alcanzado. El sacrista replicó que la mayor parte del cabildo había dado apoyo a su pretendiente, de modo que era lícito que se le proveyera de la canonjía. A pesar de la falta de acuerdo -el vicario general, entonces Guillem Grua, llegó a decir que no consentiría la provisión del canonicato en Anglada-, la prebenda fue colacionada al sobrino del sacrista aquel mismo día. Pero Cantalapiedra no se resignó, y el día siguiente presentó una suplicación al cabildo para que se le proveyera del canonicato ${ }^{75}$. Los canónigos volvieron a votar sobre aquel espinoso tema $y$, aunque el resultado volvió a ser favorable a Anglada, se inició un proceso judicial ${ }^{76}$. Incluso el rey y el papa remitieron cartas al cabildo a favor de Cantalapiedra. Si bien buena parte de los canónigos, liderados por Arnau de Santacília, afirmó que los remitentes habían sido informados contra veritatem - pues el nombramiento de Anglada contaba con el visto bueno del abogado capitular-, otros pidieron que se diera cumplimiento a las cartas. Tras una votación, se concluyó obedecer las órdenes dictadas, de modo que, en mayo de 1506, Cantalapiedra fue, finalmente, admitido en el canonicato ${ }^{77}$.

72 ACM, 01-10-ACA-016, fols. 93v-94v. El 9 de febrero de 1483 Montfort presentó el privilegio de fructibus in absencia. ACM, 01-10-ACA-016, fol. 99r.

73 Campaner y Fuertes, Cronicon Mayoricense, p. 187.

74 Otra cuestión que enfrentó al papa y los monarcas fue la provisión de prebendas a extranjeros. Los Reyes Católicos -así como sus antecesores- pretendieron que las prebendas hispánicas fueran ocupadas por personas naturales de sus reinos. De esta manera, se pretendía evitar la salida de oro y el absentismo de los titulares de aquellas. Véase Nieto Soria, Iglesia y génesis, pp. 344-348; Fernández de Córdoba Miralles, Alejandro VI, pp. 540-542 y 548; Guijarro González, "Jerarquía y redes sociales», pp. 273-274.

75 ACM, 01-10-ACA-018, fols. 97v-99r.

76 ACM, 01-10-ACA-018, fol. 106r.

77 ACM, 01-10-ACA-018, fols. 110v-111v. El 11 de diciembre de 1506 se anuló el pago del salario a Anglada attento quod postea possessio illius non habuit affectum. ACM, 01-10-ACA-018, fol. 122v. 
A pesar de ello, la situación estaba lejos de calmarse. El papa, haciendo uso de las «reservas pontificias», había decidido conceder la vacante del canonicato de Bartomeu al cardenal Giovanni Colonna y así lo notificó en julio de 1506, cuando hacía ya dos meses que Cantalapiedra poseía la prebenda. El 23 de julio los canónigos tuvieron que volver a pronunciarse sobre la sucesión en aquella canonjía. Evidentemente, Arnau de Santacília, que se había mostrado en todo momento contrario a Cantalapiedra, apoyó obedecer la carta pontificia y proveer el canonicato al cardenal, mientras que Gaspar Albertí, por su parte, propuso que el caso se remitiera a la Curia Romana, atendiendo que la prebenda había sido entregada a Cantalapiedra en virtud de una bula apostólica. Esta segunda opción resultó vencedora, de modo que el cabildo no proveyó, por el momento, al cardenal Colonna la canonjía que solicitaba ${ }^{78}$. El 11 de octubre de 1507 Llorenç Abrines, procurador del cardenal Colonna, presentó unas cartas ejecutorias al cabildo sobre la prebenda. Los canónigos, entonces, solicitaron el parecer del abogado Muntanyans ${ }^{79}$. Sea como sea, el 8 de noviembre de 1507 Llorenç Abrines presentaba las cartas apostólicas que le concedían la canonjía y la pavordía que habían sido de Antoni Francesc Bartomeu, y el 15 de noviembre siguiente tomaba posesión de las mismas ${ }^{80}$. Se ignora qué pasó con Cantalapiedra, que desaparece del listado de asistentes en las sesiones capitulares en mayo de $1507^{81}$, aunque no debió de estar conforme con su destitución, pues en 1509 todavía se hace referencia a un pleito movido por este antiguo canónigo ${ }^{82}$.

\section{Los obispos de Fernando el Católico}

De acuerdo con el Derecho Canónico y el Concilio IV de Letrán, la elección de los prelados estaba reservada al cabildo catedralicio. Sin embargo, esta prerrogativa se fue perdiendo con el tiempo como consecuencia de la injerencia tanto del rey como del papa, y, de hecho, a partir del siglo Xv los canónigos ya no intervinieron en este proceso ${ }^{83}$. Fernando II de Aragón e Isabel I de Castilla tuvieron muy clara la necesidad de controlar la elección episcopal. Ya en la Concordia de Segovia de 1475 fijaron los criterios fundamentales para la promoción de eclesiásticos a los obispados que fueran quedando vacantes en sus territorios, entre los cuales el requisito de posesión de un grado universitario ${ }^{84}$. Esto demuestra que, desde el primer momento, los reyes pretendieron dirigir el nombramiento de los prelados y promover aquellas personas que consideraran fieles y aptas para tal puesto y que podían

78 ACM, 01-10-ACA-018, fols. 113v-115r.

79 ACM, 01-10-ACA-018, fol. 130v. El abogado Muntanyans formaba parte de la prestigiosa familia de juristas. Poco después, el 9 de febrero de 1509, un Nicolau Muntanyans fue elegido abogado episcopal. ACM, 01-10-ACA-018, fol. 172r.

80 ACM, 01-10-ACA-018, fol. 133r.

81 La última referencia data del 6 de mayo de 1507. ACM, 01-10-ACA-018, fol. 127r.

82 ACM, 01-10-ACA-018, fol. 198r.

83 Olivares Terol, «El obispado de Cartagena-Murcia», p. 1156. Ver, también, Lop OTín, El cabildo catedralicio de Toledo, pp. 393-395.

${ }_{84}$ Azcona, Tarsicio de. La elección y reforma del episcopado español en tiempos de los Reyes Católicos. Madrid: Consejo Superior de Investigaciones Científicas, 1960; Nieto Soria, Iglesia y génesis, p. 372. 
LA PROVISIÓN DE CANONICATOS Y DEL OBISPADO EN MALLORCA DURANTE EL REINADO DE FERNANDO II EL CATÓLICO (1479-1516) ALBERT CASSANYES ROIG

servir de modelo para la reforma religiosa que impulsaban ${ }^{85}$. El ya comentado derecho de súplica -que fue mucho más usado en la elección episcopal que no en la de canónigos- y los más restringidos derechos de presentación y patronato concedidos por Inocencio VIII el 13 de diciembre de $1486^{86}$ fueron fundamentales para el proyecto religioso de los Reyes Católicos. Además, los monarcas exigieron un juramento de fidelidad a la Corona por parte de los nuevos obispos como requisito para la concesión de la carta ejecutoria necesaria para la toma de posesión de su diócesis ${ }^{87}$. A pesar de ello, y como en el caso de las prebendas, solo el Papado tenía capacidad para conferir la consagración, de modo que la designación de los obispos dependía, en último término, del pontífice. Frecuentemente, el papa aprovechaba aquellas vacantes episcopales para favorecer a sus allegados o recompensar a sus más leales servidores, que no siempre coincidían con los candidatos propuestos por el rey. Sin embargo, el pontífice fue cediendo cada vez más a las presentaciones reales ${ }^{88}$. Resultan evidentes, pues, los intereses, a veces contrapuestos, que reyes y papas tenían en la provisión episcopal ${ }^{89}$.

La diócesis de Mallorca no fue ajena a esta práctica, pues la monarquía también hizo valer su influencia para designar el pastor que debía regir el obispado en cada momento. Durante el reinado de Fernando II se sucedieron un total de siete prelados en la cátedra mallorquina. Sin embargo, fue un período de obispos ausentes, de modo que la diócesis era gobernada de forma ordinaria mediante vicarios generales. Cuando Fernando II accedió al trono, era titular de Mallorca Diego de Avellaneda ${ }^{90}$, que también ocupaba el cargo de canciller del monarca ${ }^{91}$. Este hecho le obligó a ausentarse de la isla, de modo que el gobierno de la diócesis era delegado en su vicario general, el canónigo Nicolau Muñoz; en el caso de que Muñoz no pudiera asistir a las sesiones capitulares -por ejemplo, por hallarse celebrando la misa-, podía ser sustituido por otro canónigo, frecuentemente el arcediano Pere Gual o el deán Bartomeu Sureda92.

Diego de Avellaneda falleció en Valladolid el 21 de noviembre de $1488^{93}$. La noticia fue comunicada al cabildo por Jaime Ramiro, notario de la corte real, y leída en sesión

85 Nieto Soria, Iglesia y génesis, p. 364.

86 Olivares Terol, «El obispado de Cartagena-Murcia», p. 1157. Los Reyes Católicos solo obtuvieron el derecho de patronato en las sedes de nueva creación -Granada, Canarias, Puerto Real, las Indias-. No fue hasta 1523 cuando Adriano VI concedió a Carlos I el patronato regio sobre todos los obispados de la Monarquía Hispánica. Lop OTín, El cabildo catedralicio de Toledo, p. 354.

87 Fernández de Córdoba Miralles, Alejandro VI, p. 541.

88 DíAz IвÁŃEz, «Iglesia y nobleza», p. 906.

89 PÉrez, Isabel y Fernando, pp. 125-133.

90 Diego de Avellaneda, elegido por el cabildo el 31 de julio de 1475 y confirmado por Sixto IV, fue el primer obispo de Mallorca no nacido en territorios de la Corona de Aragón. Mateu Mairata, Obispos de Mallorca, p. 168.

${ }_{91}$ Furió Sastre, Antonio. Episcopologio de la Santa Iglesia de Mallorca. Palma: Juan Guasp, 1852, p. 282.

92 ACM, 01-10-ACA-016, fol. 60r. El motivo más probable de que Gual y Sureda sustituyeran ordinariamente al vicario sería la titularidad de las principales dignidades de la Iglesia mallorquina.

93 Furió insiste en que Diego de Avellaneda fue trasladado del obispado de Mallorca al de Tuy, de modo que la situación de sede vacante se produciría en aquel momento. Furió SASTRE, Episcopologio, pp. 287-291. Hubo un obispo llamado Diego de Avellaneda en Tuy, pero poseyó la prelatura entre 1526 y 1537 , esto es, con posterioridad a la muerte del obispo mallorquín. 
LA PROVISIÓN DE CANONICATOS Y DEL OBISPADO EN MALLORCA DURANTE

capitular el 16 de diciembre ${ }^{94}$. El día siguiente se procedió a la elección de los distintos oficios que debían garantizar el funcionamiento ordinario de la diócesis mientras no se nombrara un nuevo prelado. Se designaron cuatro vicarios capitulares sede vacante: el arcediano Pere Gual, el deán Bartomeu Sureda, y los canónigos Nicolau Muñoz y Arnau de Santacília, doctor en ambos Derechos. Por su parte, fueron confirmados todos los distintos cargos que ejercían en el momento del traspaso del prelado ${ }^{95}$. Asimismo, se puso en funcionamiento el protocolo acostumbrado para la elección del nuevo mitrado. A pesar de que el rey Fernando deseaba para Mallorca un obispo residente ${ }^{96}$, el papa Inocencio VIII, mediante bula de 11 de octubre de 1489, nombró titular de la diócesis insular al cardenal Rodrigo de Borja ${ }^{97}$. Puesto que este no estuvo nunca presente en la isla, gobernó la diócesis a través de sus vicarios generales, los canónigos Pere Gual, Bartomeu Sureda y Gabriel Cerdà ${ }^{8}$. Sin embargo, el 14 de septiembre de 1492 se declaró el estado de sede vacante en Mallorca por la llegada de la noticia de la elección de su obispo como papa con el nombre de Alejandro $\mathrm{VI}^{99}$. El suceso causó gran regocijo en Mallorca, y el nombramiento fue celebrado con procesiones, tedeums y fiestas públicas ${ }^{100}$.

El 31 de agosto de 1492, poco más de dos semanas después de su elección papal, y cuando la noticia todavía no había llegado a Mallorca, Alejandro VI eligió el nuevo obispo de Mallorca, el cardenal genovés Giovanni Battista Savelli. Se trataba de un nombramiento personal, que no contó con la opinión del rey Fernando. Si bien el papa tuvo un cierto interés en designar personalmente los nuevos titulares de los beneficios y prebendas que había ocupado antes de su promoción pontificia ${ }^{101}$, la realidad es que el nombramiento venía motivado por la necesidad de pagar el voto del cardenal Savelli en el cónclave que había elegido a Alejandro $\mathrm{VI}^{102}$. A pesar de ello, debido a las presiones de los Reyes Católicos ${ }^{103}$, el cardenal romano renunció a la mitra el año siguiente a cambio del pago de un subsidio anual ${ }^{104}$. La ocasión fue aprovechada por Fernando II para presentar como candidato a la vacante al hasta entonces obispo de Vic, Guillem Ramon de Montcada ${ }^{105}$. En esta ocasión, Alejandro VI se avino a la propuesta real, y Montcada pudo tomar posesión del obispado el 27 de marzo de 1493.

94 ACM, 01-10-ACA-016, fol. 142v.

95 ACM, 01-10-ACA-016, fol. 175r.

96 Furió SAstre, Episcopologi, pp. 293-294. En 1484 Rodrigo de Borja había intentado ser arzobispo de Sevilla, pero se encontró con la oposición de los reyes. PÉrez, Isabel y Fernando, pp. 126-127.

${ }_{97}$ En un primer momento, fue nombrado obispo de Mallorca el bastardo de Rodrigo de Borja, César Borja. Sin embargo, el rey Fernando consiguió que se derogara el nombramiento, pues César no contaba con la edad requerida. Fue entonces nombrado su padre, en vistas a que renunciara a la mitra a favor del hijo cuando alcanzara la edad reglamentaria. SuÁrez Fernández, Luis. Los Reyes Católicos. El tiempo de la guerra de Granada. Madrid: Rialp, 1989, p. 271.

98 Mateu Mairata, Obispos de Mallorca, pp. 177-178.

99 ACM, 01-10-ACA-016, fol. 188r.

100 Mateu Mairata, Obispos de Mallorca, p. 185.

101 PÉrez, Isabel y Fernando, p. 127.

102 Fernández de Córdoba Miralles, Alejandro VI, p. 550.

103 Xamena Fiol y Riera, Història de l'Església a Mallorca, p. 77.

104 Fernández de Córdoba Miralles, Alejandro VI, p. 550.

105 Mateu Mairata, Obispos de Mallorca, p. 188. 
LA PROVISIÓN DE CANONICATOS Y DEL OBISPADO EN MALLORCA DURANTE EL REINADO DE FERNANDO II EL CATÓLICO (1479-1516) ALBERT CASSANYES ROIG

El episcopado de Montcada fue breve, pues en 1496, a petición de los Reyes Católicos, el obispo fue trasladado a la diócesis de Tarazona ${ }^{106}$-de la que tomó posesión el 16 de julio de 1496-. Sin embargo, su procurador continuó percibiendo las rentas del obispado de Mallorca, sin que los canónigos y los oficiales de la isla se opusieran. El hecho provocó una carta de reprimenda al cabildo enviada por Antonio de Rojas, obispo electo de Mallorca, el día 1 de noviembre de 1496. En esta carta, Rojas pedía a los canónigos que nombraran vicarios capitulares sede vacante para que recibieran los frutos de las rentas pertenecientes al prelado ${ }^{107}$. La problemática se prolongó durante algunos años, pues en 1498 el propio rey Fernando II tuvo que intervenir y mandar al cabildo una cédula por la que clarificaba la gracia concedida a Montcada de percibir los diezmos del año 1495. En la cédula determinó que no se exigieran más pagos por aquel concepto al cabildo de Mallorca ${ }^{108}$.

Como se ha indicado, Antonio de Rojas fue el sucesor de Guillem Ramon de Montcada al frente de la diócesis mallorquina. La presentación de su candidatura en 1496 había sido a cargo de los Reyes Católicos, pues Antonio de Rojas había sido su canciller. $\mathrm{El}$ nombramiento fue aprobado por Alejandro $\mathrm{VI}^{109}$. De la misma forma que sus predecesores, el obispo Rojas también fue ausente. A pesar de haber venido a Mallorca en 1497 para tomar posesión de la mitra ${ }^{110}$, el 14 de abril de 1499 volvió al continente, llamado por los Reyes Católicos. A tal efecto, el 5 de abril de 1499 había nombrado dos vicarios generales -el arcediano Pere Gual y el deán Bartomeu Sureda- para que administraran la diócesis hasta su regreso ${ }^{111}$. Este no tuvo lugar, pues Antonio de Rojas formaba parte del Consejo Real del rey Fernando y, por tanto, se mantuvo siempre a su lado ${ }^{112}$.

De hecho, parece ser que su relación con el monarca fue destacable, pues el rey llegó a intervenir a su favor ante el cabildo. Así pues, el 6 de agosto de 1508 Fernando el Católico envió una carta a los canónigos de Mallorca quejándose de que Antonio de Rojas no percibía las porciones canonicales a que tenía derecho por los dos canonicatos que poseía en la catedral. A pesar de que el cabildo intentó justificar el impago "por la sterilidad del tiempo», el rey no aceptó esta excusa "porque habiendo rentas para vosotros, no devía faltar para vuestro prelado». Así pues, ordenó a los canónigos que pagaran al procurador episcopal lo que se le debía. Como en todos los temas más polémicos, el cabildo se reunió y debatió sobre aquella cuestión. En la sesión se decidió enviar un canónigo al rey para informarle del estado de necesidad en que se encontraba el Reino, pues per sa acostumada clemèntia y benignitat certificada de la veritat, revocarà tal manament. El lugarteniente,

106 Tarragona, según Furió Sastre, Episcopologio, p. 298; y Campaner y Fuertes, Cronicon Mayoricense, p. 196. Se trata de una lectura incorrecta de la documentación.

107 ACM, 01-10-ACA-017, fols. 9r-10r. Antonio de Rojas informaba que todavía no había recibido las bulas pontificias que lo acreditaban como obispo de Mallorca a causa de las dificultades en los caminos.

108 ACM, 01-10-ACA-017, fol. 21r.

109 Mateu Mairata, Obispos de Mallorca, p. 194.

110 Su entrada no se celebró con ninguna fiesta, pues se guardaba duelo por la reciente muerte del príncipe Juan. Campaner y Fuertes, Cronicon Mayoricense, p. 196.

111 ACM, 01-10-ACA-017, fol. 32r.

112 Furió Sastre, Episcopologio, pp. 301-304. 
LA PROVISIÓN DE CANONICATOS Y DEL OBISPADO EN MALLORCA DURANTE

que había ido a la catedral para conocer la decisión del cabildo, consideró que aquella resolución no era acertada. Argumentando que la cantidad solicitada por el prelado no era muy elevada, y amenazando con las medidas que se vería obligado a tomar en caso de incumplimiento de la orden real, exhortó a los canónigos a deliberar de nuevo sobre la cuestión. El cabildo rechazó aquella posibilidad y, a pesar de la insistencia del lugarteniente, se ratificó en su decisión de informar al monarca de los problemas de la isla, considerando en todo momento actuar como fieles vasallos del rey ${ }^{113}$; incluso decidió enviar otro prebendado a la Curia Romana para defenderse de las acusaciones ${ }^{114}$.

Durante las semanas siguientes se llevaron a cabo los preparativos de aquellas embajadas, procediéndose a nombrar, además, los canónigos que las realizarían: Gregori Genovard a la corte real y Andreu Bibiloni a la Curia Romana. También se redactaron las debidas cartas que tenían que acompañar a los enviados, y en las que se denunciaban los ataques a las libertades e inmunidades de la Iglesia. Los preparativos se alargaron hasta el mes de diciembre ${ }^{115}$, y Genovard se trasladó a la corte en enero, regresando a Mallorca en mayo ${ }^{116}$. En la sesión capitular de 4 de mayo se leyó la carta que Genovard había conseguido del rey y mediante la cual el monarca reconocía las libertades de la Iglesia y derogaba cualquier medida que hubiera tomado que pudiera entrar en conflicto con aquellas. Ante la importancia de la carta real, los canónigos mandaron copiarla tanto en el denominado Llibre Verd ${ }^{117}$ como en la recopilación de los estatutos catedralicios. Por lo que respectaba a las demandas del obispo Rojas, el prelado y el canónigo Genovard decidieron nombrar un árbitro que dirimiera el conflicto ${ }^{118}$. Sin embargo, este nombramiento no se debió llegar a producir, pues el 11 de octubre de 1509 el cabildo decidió escribir al obispo Ribera informándole de los problemas que tenía la institución con su predecesor ${ }^{119}$.

Y es que mientras Gregori Genovard se hallaba en la corte, el cabildo fue informado de que el obispo Antonio de Rojas había sido promovido al arzobispado de Granada, siendo sustituido en la diócesis de Mallorca por el hasta entonces deán de León, Diego de Ribera ${ }^{120}$. A pesar de que la noticia fue recibida en febrero, el cabildo tuvo que activar el protocolo de sede vacante hasta la toma de posesión del nuevo prelado, que tuvo lugar dos meses más tarde, el 18 de abril de $1509^{121}$. Sin embargo, esta fue por procuración, pues Diego de Ribera nunca se trasladó a Mallorca. Sus funciones episcopales fueron ejercidas por el mallorquín Miquel Morro, obispo de Bugía ${ }^{122}$.

113 ACM, 01-10-ACA-018, fols. 152v-156r.

114 ACM, 01-10-ACA-018, fols. 157r-158v.

115 ACM, 01-10-ACA-018, fols. 162r-165v.

116 En aquellas mismas fechas también regresó el canónigo Bibiloni desde Roma.

117 No parece que llegara a copiarse, pues la carta no se halla en el mencionado volumen. SASTRE Moln, Jaume. Llibre Verd de la Seu. Palma: Publicacions Catedral de Mallorca, 2017.

${ }_{118}$ ACM, 01-10-ACA-018, fols. 178r-179r.

119 ACM, 01-10-ACA-018, fol. 198r. Parece ser que los canónigos terminaron por entregar a Antonio de Rojas las cantidades que exigía. Mateu Mairata, Obispos de Mallorca, p. 195.

120 ACM, 01-10-ACA-018, fols. 170r-171r; Campaner y Fuertes, Cronicon Mayoricense, p. 221 .

ACM, 01-10-ACA-018, fols. 176v-177v.

122 Xamena Fiol y Riera, Història de l'Església a Mallorca, p. 78. 
LA PROVISIÓN DE CANONICATOS Y DEL OBISPADO EN MALLORCA DURANTE EL REINADO DE FERNANDO II EL CATÓLICO (1479-1516) ALBERT CASSANYES ROIG

El pontificado del obispo Ribera fue también breve, pues el prelado fue trasladado al obispado de Segovia el 29 de octubre de 1511. En consecuencia, el 18 de marzo de 1512 el cabildo tuvo que proceder a declarar de nuevo el estado de sede vacante y, por tanto, eligió dos vicarios capitulares -Llorenç de Santacília y Arnau Albertí- y otros oficiales episcopales que ejercerían el cargo hasta la elección del nuevo prelado ${ }^{123}$. Este fue Rodrigo Sánchez del Mercado, consejero de Fernando II ${ }^{124}$, que tomó posesión de la mitra mallorquina el 13 de abril de $1512^{125}$. A pesar de ello, Diego de Ribera no había realizado el pago del monto obligado para la confección de una capa, de modo que se le reclamó la cantidad. No fue hasta el 3 de septiembre del mismo año cuando se realizó una ápoca para la quitación de esta deuda ${ }^{126}$.

\section{Conclusiones}

No hay ninguna duda de que el reinado de Fernando II el Católico marca la transición de la Edad Media a la Edad Moderna en la Corona de Aragón. El rey heredó de Juan II un estado medieval -aunque desde el advenimiento de la dinastía Trastámara se notaban ya algunos elementos que hacían presagiar las futuras monarquías autoritarias- y legó, a su muerte, una estructura que ya presenta las particularidades del estado moderno. En este marco hay que incluir su relación con las instituciones religiosas, que la Corona se fue preocupando de ir controlando en el marco de su política religiosa reformista. Uno de los pilares imprescindibles en este sentido era el nombramiento de los distintos cargos eclesiásticos, especialmente los obispos, que tendrían que ejecutar las disposiciones que los monarcas imponían ${ }^{127}$. A tal efecto, los reyes hicieron uso del derecho de súplica $-\mathrm{y}$ del derecho de patronato cuando fue posible-, entre otras medidas $^{128}$.

El cabildo de Mallorca no era una institución individual, sino integrada por veintidós canónigos. Precisamente, uno de los principales objetivos del presente artículo era concretarlos, establecer su nómina y sistematizar su sucesión. A partir de la singularización de cada prebendado, es posible estudiar cada canónigo de forma particular para, seguidamente, hallar los puntos comunes mediante la elaboración de una prosopografía de todos los miembros del cabildo. Este artículo ya ha indicado algunos elementos, entre los cuales cabe mencionar la importancia de la formación universitaria, mayormente de los grados en Derecho Canónico. Tampoco puede olvidarse el rol fundamental que las

123 ACM, 01-10-ACA-019, fol. 72r-v.

124 Mateu Mairata, Obispos de Mallorca, p. 209.

125 ACM, 01-10-ACA-019, fol. 78r-v.

126 ACM, 01-10-ACA-019, fol. 96r.

127 Lop Otín, El cabildo catedralicio de Toledo, pp. 353-354.

128 Los Reyes Católicos también intentaron, sin éxito, la modificación de las demarcaciones diocesanas. Barrio Gozalo, Maximiliano. El sistema beneficial de la Iglesia española en el Antiguo Régimen (1475-1834). Alicante: Publicaciones Universidad de Alicante, 2011, pp. 27-29. Sin embargo, las insistencias de Fernando el Católico se encuentran detrás de la elevación de Orihuela a la categoría de sede catedralicia en 1510. Olivares Terol, «El obispado de Cartagena-Murcia», pp. 1153-1154. 
LA PROVISIÓN DE CANONICATOS Y DEL OBISPADO EN MALLORCA DURANTE EL REINADO DE FERNANDO II EL CATÓLICO (1479-1516) ALBERT CASSANYES ROIG

estrategias familiares de promoción social jugaban, y que se hallan, en muchas ocasiones, en el origen de la provisión de las canonjías en determinadas personas.

Sin embargo, no hay que menospreciar el papel del rey y del papa, que hicieron de estas provisiones una extensión de sus sólitamente convulsas relaciones diplomáticas. El monarca estaba interesado en disponer de clérigos afines en los distintos cabildos catedralicios para lograr apoyos a su política, pero también para premiar servicios prestados. La pretensión de controlar la colación de las prebendas y de los beneficios en general -así como de la Iglesia entera- no fue un rasgo particular del reinado de los Reyes Católicos, sino que constituía una práctica habitual en los reinos europeos ya desde el Cisma de Occidente ${ }^{129}$.

Los papas también harían uso de las prebendas para promocionar a sus allegados. El caso más destacado fue el de Rodrigo Borja -Alejandro VI-, que utilizaría su influencia para conseguir que sus familiares obtuvieran prebendas mallorquinas. Este fue el caso, según el Llibre de Possessoris, del canónigo subdiaconil Borja, que resignó su prebenda en $1481^{130}$. No es posible determinar quién sería este Borja, aunque se mencionan varias dignidades con este apellido que, sin embargo, no pueden ser vinculadas a esta resignación por motivos cronológicos. Así pues, con anterioridad a 1481, se nombró a Joan de Borja, que permutaría el deanato de Mallorca con Bartomeu Sureda hacia $1472^{131}$. Joan de Borja también aparece como precentor de la catedral entre 1478 y 1486, año en que resignaría a favor de César Borja, que tomaría posesión de esta dignidad el 9 de junio de 1486, y que la poseyó hasta 1505, cuando la cedería a Llorenç de Santacília ${ }^{132}$. En abril de 1494 habría sido nombrado sacrista Jofré de Borja, aunque este resignaría en noviembre del mismo año a favor de Francesc Grasset ${ }^{133}$. Finalmente, desde el 16 de marzo de 1496 sería sucentor Francesc de Borja, también cardenal; este renunciaría en $1505^{134}$.

Los poderes, pero, tenían un mayor interés en el nombramiento de los obispos. En un primer momento, parece que Alejandro VI quiso imponer sus propios candidatos, como hizo con el cardenal Savelli. Sin embargo, pronto el pontífice se doblegó a los intereses de Fernando II y accedió, de forma ordinaria, a la ratificación del aspirante propuesto por el monarca haciendo uso del derecho de súplica ${ }^{135}$. Evidentemente, el rey promovió a la mitra mallorquina a clérigos que le eran afines y que se hallaban a su servicio, como Antonio de Rojas - canciller de los monarcas- o Rodrigo Sánchez del Mercado -consejero real-. Así pues, el obispado de Mallorca fue utilizado por Fernando II como premio transitorio de sus allegados, a la espera de poder ser trasladados a un destino más

129 Rapp, La Iglesia y la vida religiosa, pp. 56-58; Nieto Soria, Iglesia y génesis, pp. 18-19.

130 ACM, 15576, fol. 76r.

131 ACM, 15576, fol. 7r.

132 ACM, 15576, fol. 10r. Esta resignación también era un favor, pues el procurador de César Borja en Mallorca era Jordi de Santacília. ACM, 1764, fol. 26r.

133 ACM, 15576, fol. 4r.

134 ACM, 15576, fol. 82r.

135 Fernández de Córdoba Miralles, Alejandro VI, p. 554. A pesar de no contar con el patronato regio, la mayor parte de los obispos presentados por los Reyes Católicos fueron aceptados por Roma. Lop Otín, El cabildo catedralicio de Toledo, p. 404. 
LA PROVISIÓN DE CANONICATOS Y DEL OBISPADO EN MALLORCA DURANTE EL REINADO DE FERNANDO II EL CATÓLICO (1479-1516) ALBERT CASSANYES ROIG

prestigioso ${ }^{136}$. Esto explicaría que buena parte de los prelados mallorquines de este período no falleciera durante la titularidad de la mitra insular, sino que su episcopado finalizó por la asignación de nuevos destinos: Guillem Ramon de Montcada fue trasladado a Tarazona; Antonio de Rojas, al recién creado arzobispado de Granada; Diego de Ribera, a Segovia. El cabildo catedralicio, supuesto órgano competente en la elección episcopal, no tuvo en ningún momento la iniciativa de proceder a nombrar el obispo. De hecho, los Reyes Católicos no permitieron la designación de prelado por parte del cabildo sin la previa autorización real ${ }^{137}$.

Un aspecto a mencionar, quizá consecuencia de esta injerencia real en el nombramiento de obispos, es la ausencia de prelados mallorquines. El último natural de la isla en poseer la mitra mallorquina fue Arnau de Marí (1460-1464), mientras en 1475 la promoción del obispo Diego de Avellaneda implicó la llegada del primer mitrado no originario de los territorios de la Corona de Aragón. Esta proliferación de peninsulares y extranjeros en la cátedra episcopal no se dio de forma tan significativa en el cabildo catedralicio, que estuvo integrado, mayoritariamente, por mallorquines, aunque esto no implica que no se concedieran también canonicatos a personas de fuera de la isla. Este hecho podría explicarse por el escaso interés que debía ofrecer una prebenda en Mallorca, un territorio separado por el mar, periférico y lejano del centro de poder que representaba Castilla ${ }^{138}$. Este mismo temor al aislamiento político también se halla, en buena parte, en la explicación de que los obispos tampoco hicieran amago de trasladarse a Mallorca tras su designación ${ }^{139}$.

No en vano, hubo muchos canónigos que no estuvieron presentes en la isla. Incluso algunos no tenían la intención de trasladarse a la diócesis, como demuestra la rapidez en que presentaron sus respectivos privilegios de fructibus in absencia. Por ejemplo, Joan Girona fue admitido en el canonicato el 28 de febrero de 1493, y el 5 de marzo su procurador Jaume Seguí ya entregaba el mencionado privilegio $^{140}$. Otros, en cambio, lo presentaron a lo largo de su posesión del cargo, a medida que las circunstancias los obligaban a ausentarse de la isla. Generalmente, el privilegio se refería a un tiempo limitado, como fue el caso de Francesc Net, cuyo privilegio solo tenía una vigencia de dos ańos ${ }^{141}$. A pesar de que estas gracias siempre fueron admitidas por el cabildo, en una ocasión se menciona la oposición de un canónigo: sucedió el 7 de mayo de 1505, cuando Guillem Grua protestó por la aceptación del privilegio de fructibus in absencia que había presentado Joan Andreu Bibiloni ${ }^{142}$.

Otro elemento a destacar es la importancia del oficio del abogado capitular. Los canónigos acudían seguidamente a este para que los asesorara jurídicamente y validara

136 Este hecho también se documenta en otras diócesis hispanas, como Palencia. Francia LoRenzo, Santiago. «El cabildo palentino en el siglo XV». Publicaciones de la Institución Tello Téllez de Meneses, 1988, vol. 59, p. 147.

137 Nieto Soria, Iglesia y génesis, p. 373.

138 En otras diócesis, el clero del lugar estuvo escasamente representado en el cabildo. Díaz IвÁŃEZ, «Iglesia y nobleza», p. 925.

139 Furió Sastre, Episcopologio, p. 330.

140 ACM, 01-10-ACA-016, fol. 189v.

141 ACM, 01-10-ACA-018, fol. 147v.

142 ACM, 01-10-ACA-018, fol. 82v. 
LA PROVISIÓN DE CANONICATOS Y DEL OBISPADO EN MALLORCA DURANTE EL REINADO DE FERNANDO II EL CATÓLICO (1479-1516) ALBERT CASSANYES ROIG

sus resoluciones. Esta trascendencia se observa, sobre todo, en el momento de proveer los canonicatos vacantes en función de los derechos que presentaba cada aspirante. Incluso el hecho de que el abogado apoyara una decisión capitular era esgrimido como argumento ante una protesta. Otra cuestión es que el cargo recayó en miembros de destacadas familias de juristas, como los Muntanyans -a la que pertenecía Jaume Muntanyans- o los Mília -representados por Francesc Mília ${ }^{143}-$.

En definitiva, el cabildo catedralicio de Mallorca durante el reinado de Fernando II siguió la tónica general de los cabildos hispánicos, aunque matizada por sus circunstancias particulares, esencialmente geográficas. La periferia del archipiélago alejó la diócesis del centro de poder, de modo que pudo librarse de los intereses prioritarios tanto de los monarcas - no parece que la reforma religiosa de los Reyes Católicos tuviera demasiada incidencia en el organismo- como de las principales familias nobiliarias ${ }^{144}$. De hecho, el cabildo se nutrió, básicamente, de canónigos procedentes de linajes mallorquines, dando lugar a una institución endogámica y oligárquica. La ausencia de los obispos coadyuvó a reforzar el rol de poder que los canónigos pudieron ostentar.

\section{REFERENCIAS BIBLIOGRÁFICAS}

Azcona, Tarsicio de. La elección y reforma del episcopado español en tiempos de los Reyes Católicos. Madrid: Consejo Superior de Investigaciones Científicas, 1960.

Barceló Crespí, Maria. Els Llitrà. Una nissaga de notaris a la Mallorca baixmedieval. Palma: Lleonard Muntaner, editor, 2001.

Barceló Crespí, Maria y Ensenyat Pujol, Gabriel. «Els Mília. Una altra nissaga de notaris a la Mallorca medieval». En Ferrando Ballester, Catalina (ed.). Homenatge a Guillem Rosselló Bordoy. Palma: Govern de les Illes Balears, 2002, pp. 177-191.

Barceló Crespí, Maria y Ensenyat Pujol, Gabriel. Clergues il.lustrats. Un cercle humanista a l'entorn de la Seu de Mallorca (1450-1550). Palma: Publicacions Catedral de Mallorca, 2013.

Barrio Gozalo, Maximiliano. El sistema beneficial de la Iglesia española en el Antiguo Régimen (1475-1834). Alicante: Publicaciones Universidad de Alicante, 2011.

Bello León, Juan Manuel. «Apuntes para el estudio de la influencia del corso y la piratería en la política exterior de los Reyes Católicos». Historia. Instituciones. Documentos, 1996, vol. 23, pp. 63-97.

Campaner y Fuertes, Álvaro. Cronicon Mayoricense. Noticias y relaciones históricas de Mallorca desde 1229 a 1800. Palma de Mallorca: [Edic. de Ayer] 1967

Cassanyes Roig, Albert. «El Capítol catedralici de Mallorca a la segona meitat del segle XV». Anuario de Estudios Medievales, en prensa.

Cassanyes Roig, Albert. «El Capítol catedralici de Ramon Llull (1232-1316)». En Fullana Puigserver, Pere y Gambús Saiz, Mercè (coords.). Ramon Llull i la Seu de Mallorca. Palma: Publicacions Catedral de Mallorca, 2016, pp. 43-77.

Cassanyes Roig, Albert. «Nicolau Espanyol: una canongia accidentada (1380-1391)». En Carbonell, Natàlia; Castaño, Marta; Duarte-Feitoza, Paulo H.; Perera Roura, Anna y

143 ACM, 01-10-ACA-019, fol. 111r.

144 Quizá se pueda hallar en este hecho la relativamente escasa movilidad del clero mallorquín, a diferencia del fenómeno observado en Burgos por GuijARro GonZÁLEZ, "Jerarquía y redes sociales», pp. 281-282. 
LA PROVISIÓN DE CANONICATOS Y DEL OBISPADO EN MALLORCA DURANTE EL REINADO DE FERNANDO II EL CATÓLICO (1479-1516) ALBERT CASSANYES ROIG

VIÑolas, Mariona (eds.). Investigar les Humanitats: viure a fons la humanitat. Girona: Universitat de Girona, 2016, pp. 48-60.

Cepeda Adán, José. En torno al concepto del estado en los Reyes Católicos. Madrid: Fundación Española de Historia Moderna-Consejo Superior de Investigaciones Científicas, 2010.

Clavero Salvador, Bartolomé. «Institución, política y derecho. Acerca del concepto historiográfico de "Estado Moderno"». Revista de Estudios Políticos, 1981, vol. 19, pp. 43-57.

Deyà BauzÀ, Miquel J. «Entre la toma de Orán y los pactos con Argel: las Baleares y la conquista de Bugía». En Bunes Ibarra, Miguel Ángel de y Alonso Acero, Beatriz (coords.). Orán. Historia de la corte chica. Madrid: Polifemo, 2011, pp. 55-82.

DíAz IвÁŃEZ, Jorge. «Iglesia y nobleza en la Sevilla bajomedieval». Anuario de Estudios Medievales, 2009, vol. 39, n. ${ }^{\circ}$ 2, pp. 877-931.

Fernández de Córdoba Miralles, Álvaro. Alejandro VI y los Reyes Católicos. Relaciones políticoeclesiásticas (1492-1503). Roma: Edizioni Università della Santa Croce, 2005.

Francia Lorenzo, Santiago. «El cabildo palentino en el siglo XV». Publicaciones de la Institución Tello Téllez de Meneses, 1988, vol. 59, pp. 143-178.

Furió Sastre, Antonio. Episcopologio de la Santa Iglesia de Mallorca. Palma: Juan Guasp, 1852.

García Oró, José. Cisneros y la reforma del clero español en tiempo de los Reyes Católicos. Madrid: Consejo Superior de Investigaciones Científicas, 1971.

García Oró, José. La reforma de los religiosos españoles en tiempo de los Reyes Católicos. Valladolid: Instituto Isabel la Católica de Historia Eclesiástica, 1969.

Guijarro GonzÁlez, Susana. "Jerarquía y redes sociales en la Castilla medieval: la provisión de beneficios eclesiásticos en el cabildo de la catedral de Burgos (1390-1440)». Anuario de Estudios Medievales, 2008, vol. 38, n.o 1, pp. 271-299.

Iglesias Ortega, Arturo. "Cómo llegar a ser canónigo en el siglo xvi: formas de ingreso en el cabildo de la catedral de Santiago de Compostela». Cuadernos de Historia Moderna, 2014, vol. 39, pp. 77-104.

Iglesias OrTEga, Arturo. El cabildo catedralicio de Santiago de Compostela en el siglo XVI: aspectos funcionales y sociológicos de una élite eclesiástica. Santiago de Compostela: Universidade de Santiago de Compostela, 2010 (tesis doctoral).

Ladero Quesada, Miguel Ángel. La España de los Reyes Católicos. Madrid: Alianza, 2005.

Lop Otín, María José. El cabildo catedralicio de Toledo en el siglo XV: aspectos institucionales y sociológicos. Madrid: Universidad Complutense de Madrid, 2001 (tesis doctoral).

Marí Cardona, Joan. La conquesta catalana de 1235. Ibiza: Institut d'Estudis Eivissencs, 1976.

MARKs, Robert B. Los origenes del mundo moderno. Una nueva visión. Barcelona: Editorial Crítica, 2007.

Martín Corrales, Eloy. «La defensa de las costas, del tráfico marítimo y de los súbditos frente al corso musulmán en la España de la Edad Moderna». Coloquio de Historia Canario-Americana, 2008, vol. 17, pp. 1854-1882.

Mateu Mairata, Gabriel. Obispos de Mallorca. Palma: Ediciones Cort, 1985.

Navarro Sorní, Miguel. «La creación de la archidiócesis valentina. La Iglesia valenciana en el siglo XV». Anales Valentinos, 1992, vol. 18, pp. 287-304.

Nieto Soria, José Manuel. Iglesia y génesis del estado moderno en Castilla (1369-1480). Madrid: Editorial Complutense, 1993.

Olivares Terol, María José. «El obispado de Cartagena-Murcia y su cabildo catedralicio. Formación y evolución en el transcurso de la Edad Media». Anuario de Estudios Medievales, 1997, vol. 27, pp. 1149-1175.

Palou Santandreu, Jaume. «Els Montanyans i el cercle d'humanistes. Una família poderosa a finals de l'Edat Mitjana». En Barceló Crespí, Maria (coord.). Al tombant de l'Edat 
LA PROVISIÓN DE CANONICATOS Y DEL OBISPADO EN MALLORCA DURANTE

Mitjana. Tradició medieval i cultura humanista. Palma: Institut d'Estudis Baleàrics, 2000, pp. 451-468.

PÉrez, Joseph. Isabel y Fernando. Los Reyes Católicos. Madrid: Nerea, 2001.

Planas Rosselló, Antonio. Los jurados de la Ciudad y Reino de Mallorca (1249-1718). Palma: Lleonard Muntaner, editor, 2005.

Ramis Barceló, Rafael. «Peregrinatio academica: legistas y canonistas de la Corona de Aragón en las universidades italianas durante el Renacimiento». Miscellanea Historico-Iuridica, 2014, vol. 13, pp. 35-66.

Rapp, Francis. La Iglesia y la vida religiosa en Occidente a fines de la Edad Media. Barcelona: Labor, 1973.

Sánchez Doncel, Gregorio. Presencia de España en Orán (1509-1792). Toledo: Estudio Teológico de San Ildefonso, 1991.

Sastre Moll, Jaume. Llibre Verd de la Seu. Palma: Publicacions Catedral de Mallorca, 2017.

STrayer, Joseph R. Sobre los orígenes medievales del Estado moderno. Barcelona: Ariel, 1986.

SuÁrez Fernández, Luis. Los Reyes Católicos. El tiempo de la guerra de Granada. Madrid: Rialp, 1989.

Val Valdivieso, María Isabel del. «Isabel la Católica. Una mujer para el trono de Castilla». Memòries de la Reial Acadèmia Mallorquina d'Estudis Genealògics, Heràldics i Històrics, 2004, vol. 14, pp. 7-23.

Xamena Fiol, Pere y Riera, Francesc. Història de l'Església a Mallorca. Palma: Editorial Moll, 1986. 